J. Egypt. Soc. Parasitol. (JESP), 51(2), 2021: 411 - 416

(Online: 2090-2549)

\title{
HEPATOCELLULAR CARCINOMA INCIDENCE IN HEPATITIS C PATIENTS TREATED WITH DIRECT-ACTING ANTIVIRALS AND ITS RELATIONSHIP TO HEPATIC FIBROSIS STAGE
}

By

YASSER O. ABDELRAHMAN ${ }^{1}$, MAZEN M. ELSHEIKH ${ }^{1}$, AMAL SH. BAKER $^{1}$, MOSTAFA SH. AHMED ${ }^{2}$, MAHA A. ELTOUNY ${ }^{1}$, and AYMAN G. A. DAWOD ${ }^{1 *}$

Department of Internal Medicine, HepatogastroenterologyandEndoscopy ${ }^{1}$, Faculty of Medicine,Ain ShamsUniversity, Cairo 115656, and Military Medical Academy'2, Cairo, 11291, Egypt ( ${ }^{*}$ Correspondence: Ayman.gamil@med.asu.edu.eg).

\begin{abstract}
The Hepatitis $\mathrm{C}$ virus (HCV) has a major impact on public health and is thought to be responsible for $25 \%$ of hepatocellular carcinoma (HCC) and $27 \%$ of cirrhosis cases worldwide. Recent direct-acting antivirals (DAAs) for hepatitis $\mathrm{C}$ have the potential to reduce this disease burden, but there are increased worries about HCC incidence in HCV patients receiving DAAs. This work assessed the HCC incidence in HCV patients treated with DAAs and its relationship to Hepatic Fibrosis Stage.

The study included 400 chronic HCV patients equally divided into two groups: chronic $\mathrm{HCV}$ patients who did not receive anti HCV medication (control group) and chronic HCV patients who received different DAAs treatment regimens. There was a highly significant difference between both groups as regards hepatic fibrosis stages before DAAs therapy. The DAA receiving group had highly statistically advanced hepatic fibrosis when compared to the control group. After eighteen months of follow up, the DAA receiving group had a significantly lower incidence of HCC when compared to the control group $(5.5 \%$ versus $11 \%$ respectively, p-value 0.04).
\end{abstract}

Key words: Hepatitis C virus (HCV), Hepatocellular carcinoma (HCC), Hepatic fibrosis, Direct-acting antivirals (DAAs).

\section{Introduction}

HCV has a major impact on public health with $<170$ million infected patients (Sagnelli et al, 2020). It was responsible for $25 \%$ of hepatocellular carcinoma (HCC) \& $27 \%$ of liver cirrhosis cases (Page et al, 2021). Egypt has one of the world's highest rates of hepatitis $\mathrm{C}$ virus (HCV) infection (Raad et $a l$, 2018). Genotype 4 is the commonest of the six major HCV genotypes, with $4 \mathrm{a}$ as the dominant subtype (Omran et al, 2018).

Cirrhosis developed about $16 \%$ of patients with chronic HCV infection over last 2 decades (Kwo et al, 2017). Westbrook and Dusheiko (2014) in UK reported that HCC and hepatic de-compensation were linked to annual cirrhosis risk $(3-5 \%$ \& 3-6\%, respectively), the incidence of HCC was reduced in chronic hepatitis $\mathrm{C}$ genotype 4 patients with liver cirrhosis (F4) and advanced hepatic fibrosis (F3) who achieved SVR followed the DAA therapy.

For a decade or more, peg-interferonbased therapy was the cornerstone of $\mathrm{HCV}$ treatm-ent, but due to low SVR rates, treatment in cirrhotic patients has been difficult (Kim et al, 2011). Di Bisceglie et al. (2011) in USA added that Long-term maintenance peginterferon in patients with advanced chronic hepatitis $\mathrm{C}$ is associated with an excess overall mortality, which was primarily due to nonliver-related causes among patients with bridging fibrosispeople with advanced liver disease, who are in need of treatment, are unable to tolerate interferon because of the high risk of sepsis, liver failure, and mortality. However, advances in understanding of HCV's molecular virology, life cycle, and pathogenesis resulted in a new era of anti HCV medications, the Direct-Acting Antiviral or DAA (Hezode et al, 
2015). Currently, an approved interferonfree treatment for cirrhosis patients that is all-oral, highly effective and well-tolerated, including various DAA regimens, is becoming a reality (Majumdar et al, 2016). Although, it was expected that of HCV- rates associated HCC decreased significantly after widespread use of DAAs, but Kozbial et al. (2016) in Austria reported that hepatitis C patients with cirrhosis treated with directacting antivirals have a higher risk of getting HCC. Tayyab et al. (2020) in Pakistan reported that conflicting data regarding the risk of hepatocellular carcinoma (HCC) after direct-acting antiviral agent (DAA) treatment. Risk of HCC in HCV genotype-3 infected persons after DAA therapy is not well known. They added that In a predominantly genotype 3 cohort, incident HCC occurred frequently and early after treatment completion, and exclusively in those with pretreatment cirrhosis. SVR reduced the risk of HCC. Treating HCV infected persons before development of cirrhosis may reduce risk of HCC. This increased the worries about HCC incidence in HCV patients, but few studies on Egyptian patients have been published. In whom other predominant $\mathrm{HCV}$ genotypes are found and different treatment protocols are followed (Waked et al, 2020).

This study aimed to assess the incidence of Hepatocellular Carcinoma in patients infected with $\mathrm{HCV}$, receiving treatment with Direct-Acting Antivirals and its relationship to Hepatic Fibrosis Stage.

\section{Patients and Methods}

The retrospective study included 400 chronic HCV patients from Hepatology Outpatient Clinic, Kobri El-Koba Military Campus from January 2018 to September 2019. They were chosen based on the following criteria: Both sexes over 18years old with HCV PCR positive and had completed follow up including pelvi-abdominal ultrasound for at least 18 months. If patients had any of the following conditions, they were ruled out of the study: severe decompensated hepatic conditions (defined as total serum bilirubin $<3 \mathrm{mg} / \mathrm{dl}$ or serum albumin $<2.5 \mathrm{~g} / \mathrm{dl}$ or International Normalized Ratio INR $>1.7$, patients who did not complete Direct Acting Antivirals treatment course, HBV co-infected patients, and patien-ts with an active or previous history of HCC.

All patients were divided into two groups. GI: Chronic HCV patients who received different DAAs regimens either for 12 or 24 weeks according to the National Guidelines. GII: chronic HCV patients who did not receive anti HCV medication (control).

Treatment were sofosbuvir/daclatasvir, sofosbuvir/daclatasvir/ribavirin,sofosbuvir/ledipasvir, sofosbuvir/ledipasvir/ribavirin, sofosbuvir/ribavirin \& sofosbuvir/simeprevir.

All were given questioners: a- name, bage, c- martial status to assess contraception need, d- occupations as simperevir containing regimens to avoid those with frequent sun exposure., e- residences to ensu-re patients' treatment and follow-up schedu-les, fsubstance abuse as patients with substance abuse were co-managed by a psychiatrist, ghistory of chronic liver disease and /or hepatic de-compensation, h- diabetes history, $\&$ i- hypertension and cardiac diseases. Then they were clinically examined.

Laboratory tests: They were examined for $\mathrm{CBC}$, liver profile, HCVAb \& HBsAg, Serum alpha-Fetoprotein (AFP), kidney function tests, fasting blood sugar, $\mathrm{HbA}-1 \mathrm{C}$, pregnancy test for females bearing child, $\mathrm{HCV} / \mathrm{PCR}$ (quantitative), ECG for males $\geq$ 40 years old and females $\geq 50$, and echocardiography for patients $\geq 60$ years.

All patients underwent a pelvi-abdominal ultrasound prior to the study and six, twelve, and eighteen months after to screen hepatic focal lesion. Triphasic CT or Dynamic MRI was done if hepatic focal lesions were detected to exclude HCC. Transient elastography was done for all to identify hepatic fibrosis stages. Upper GI endoscopy was done for all to detect the prevalence of esophageal varices.

Ethics approval and consent: All procedures were carried out in accordance with 
the ethical standards of Ain Shams University Research Committee, and 1964 Helsinki Declaration and its subsequent amendments. Ethics reference number was 000017585. All patients gave their written consent.

Statistical analysis: IBM SPSS software program version 20.0 examined data into the computer (IBM Corporation, Armonk, NY). Number and percent described qualitative data. For normal distribution Kolmogorov-
Smirnov test was used. Data were described as minimum \& maximum, $\mathrm{M} \pm \mathrm{SD}$, and median by using Chi-square test, Fisher's Exact or Monte Carlo correction and Student t-test. Significance level was expressed as: $\mathrm{P} \geq$ $0.05=$ insignificant, $\mathrm{P}<0.05=$ significant $\&$ $\mathrm{P}<0.01=$ highly significant.

The details were given in tables $(1,2, \& 3)$ and figure (1)

\section{Results}

Table 1: Difference between GI \& GII as to ascites, splenomegaly \& esophageal varices.

\begin{tabular}{|l|l|l|l|l|l|}
\hline \multicolumn{2}{|l|}{ Clinical finding } & DAA receiving (GI) & Controls (GII) & Test value & \multirow{2}{*}{ P-value } \\
\cline { 3 - 4 } \multicolumn{2}{l|}{ Ascites } & No. $=200$ & No. $=200$ & & \\
\cline { 2 - 4 } & No & $199(99.5 \%)$ & $200(100.0 \%)$ & \multirow{2}{*}{$1.003^{*}$} & 0.317 \\
\hline \multirow{2}{*}{ Splenomegaly } & No & $1(0.5 \%)$ & $0(0.0 \%)$ & & \\
\cline { 2 - 4 } & Yes & $168(84.0 \%)$ & $157(78.5 \%)$ & $1.986^{*}$ & 0.159 \\
\hline \multirow{2}{*}{ Esophageal varices } & No & $190(16.0 \%)$ & $43(21.5 \%)$ & & \\
\cline { 2 - 4 } & Yes & $10(5.0 \%)$ & $183(91.5 \%)$ & $1.946^{*}$ & 0.163 \\
\hline
\end{tabular}

Pre-treatment endoscopic and ultrasound ascites, and splenomegaly, were without results as prevalence of esophageal varices, significant difference between both groups.

Table 2: Difference between GI \& GII as to age \& laboratory results before treatment.

\begin{tabular}{|c|c|c|c|c|c|}
\hline \multicolumn{2}{|l|}{ Variables } & \multirow{2}{*}{\begin{tabular}{|l|} 
DAA receiving (GI) \\
No. $=200$ \\
$63.02 \pm 6.86$
\end{tabular}} & \multirow{2}{*}{$\begin{array}{l}\text { Controls (GII) } \\
\text { No. }=200 \\
64.24 \pm 6.49\end{array}$} & \multirow{3}{*}{$\begin{array}{l}\text { Test value } \\
-1.827 \bullet\end{array}$} & \multirow{3}{*}{$\begin{array}{l}\text { P-value } \\
0.068\end{array}$} \\
\hline \multirow{2}{*}{ Age } & $\mathrm{M} \pm \mathrm{SD}$ & & & & \\
\hline & Range & $37-77$ & $38-83$ & & \\
\hline \multirow[t]{2}{*}{$\mathrm{Hb}$} & $\mathrm{M} \pm \mathrm{SD}$ & $14.08 \pm 1.59$ & $14.29 \pm 1.49$ & \multirow[t]{2}{*}{$-1.345 \bullet$} & \multirow[t]{2}{*}{0.180} \\
\hline & Range & $8.2-17.3$ & $10.1-18.4$ & & \\
\hline \multirow[t]{2}{*}{ PLT } & $\mathrm{M} \pm \mathrm{SD}$ & $177.65 \pm 61.95$ & $170.59 \pm 69.81$ & \multirow[t]{2}{*}{$1.069^{\bullet}$} & \multirow[t]{2}{*}{0.286} \\
\hline & Range & $55-397$ & $14.7-483$ & & \\
\hline \multirow[t]{2}{*}{ ALT } & Median (IQR) & $35(27-63)$ & $48(30.5-65)$ & \multirow[t]{2}{*}{$-2.317 \neq$} & \multirow[t]{2}{*}{0.020} \\
\hline & Range & $7-245$ & $9-164$ & & \\
\hline \multirow[t]{2}{*}{ AST } & Median (IQR) & $37(29-63.5)$ & $42(29-67)$ & \multirow[t]{2}{*}{$-0.710 \neq$} & \multirow[t]{2}{*}{0.478} \\
\hline & Range & $15-169$ & $10-198$ & & \\
\hline \multirow[t]{2}{*}{ Serum Creatinine } & $\mathrm{M} \pm \mathrm{SD}$ & $0.94 \pm 0.22$ & $1.00 \pm 0.56$ & \multirow[t]{2}{*}{$-1.411 \bullet$} & \multirow[t]{2}{*}{0.159} \\
\hline & Range & $0.5-1.9$ & $0.5-7.4$ & & \\
\hline \multirow[t]{2}{*}{ Total bilirubin } & $\mathrm{M} \pm \mathrm{SD}$ & $0.92 \pm 0.48$ & $0.83 \pm 0.41$ & \multirow[t]{2}{*}{$2.080 \bullet$} & \multirow[t]{2}{*}{0.038} \\
\hline & Range & $0.3-2.8$ & $0.4-2.6$ & & \\
\hline \multirow[t]{2}{*}{ Direct bilirubin } & $\mathrm{M} \pm \mathrm{SD}$ & $0.32 \pm 0.15$ & $0.30 \pm 0.17$ & \multirow[t]{2}{*}{$0.913 \bullet$} & \multirow[t]{2}{*}{0.362} \\
\hline & Range & $0.14-0.9$ & $0.07-2.25$ & & \\
\hline \multirow[t]{2}{*}{ INR } & $\mathrm{M} \pm \mathrm{SD}$ & $1.17 \pm 0.19$ & $1.07 \pm 0.10$ & \multirow[t]{2}{*}{$6.797 \bullet$} & \multirow[t]{2}{*}{0.000} \\
\hline & Range & $0.91-1.76$ & $0.86-1.69$ & & \\
\hline \multirow[t]{2}{*}{ Albumin } & $\mathrm{M} \pm \mathrm{SD}$ & $4.12 \pm 0.67$ & $4.24 \pm 0.44$ & \multirow[t]{2}{*}{$-2.191 \bullet$} & \multirow[t]{2}{*}{0.029} \\
\hline & Range & $2.5-5.33$ & $2.5-5.2$ & & \\
\hline AFP & Median (IQR), Range & $5(4-8) 2-23$ & $6(4-9) 2-23$ & $-0.767 \neq$ & 0.443 \\
\hline \multirow[t]{2}{*}{ PCR } & Median (IQR) & $800000(175000-2000000)$ & $546037(110500-1761339)$ & $-0.948 \neq$ & 0.343 \\
\hline & Range & $1000-14000000$ & $1000-29000000$ & & \\
\hline
\end{tabular}

$\bullet$ : Independent t-test; $\neq$ : Mann-Whitney test

Patients received DAA showed significant tal bilirubin, International Normalized Ratio difference compared to controls as ALT, to- (INR) and serum albumin.

\begin{tabular}{|c|c|c|c|c|}
\hline \multirow{2}{*}{$\begin{array}{l}\text { Hepatic fibrosis } \\
\text { stage }\end{array}$} & DAA receiving (GI) & Controls (GII) & \multirow[t]{2}{*}{ Test value } & \multirow[t]{2}{*}{ P-value } \\
\hline & No. $=200$ & No. $=200$ & & \\
\hline F0 & $9(4.5 \%)$ & $41(20.5 \%)$ & \multirow[t]{5}{*}{$43.413^{*}$} & \multirow[t]{5}{*}{0.000} \\
\hline F1 & $28(14.0 \%)$ & $28(14.0 \%)$ & & \\
\hline $\mathrm{F} 2$ & $14(7.0 \%)$ & $37(18.5 \%)$ & & \\
\hline F3 & $23(11.5 \%)$ & $13(6.5 \%)$ & & \\
\hline F4 & $126(63.0 \%)$ & $81(40.5 \%)$ & & \\
\hline
\end{tabular}


A highly significant difference was between groups as to hepatic fibrosis stages before DAA therapy, and Transient elastography both groups. DAA receiving group showed highly significant advanced hepatic fibrosis as compared to control. After 18 months of follow up, DAA receiving group after 18 months follow-up showed lower HCC incidence $\mathrm{P}=0.04$ ) as compared to control with $5.5 \%$ vs. $11 \%$ respectively (Fig. 1 ).

\section{Discussion}

Although direct acting antivirals (DAA) have provided highly efficacious, well tolerated treatment for chronic $\mathrm{HCV}$ patients (Majumdar et al, 2016), worries about the increased likelihood of hepatocellular carcinoma (HCC) after DAA regimens (Tayyab et al, 2020) (Kozbial et al, 2016). HCC after DAA therapy was also suggested to have greater liver stiffness (Conti et al, 2016). The aim of our study is to investigate the HCC incidence after DAA therapy in Egyptian chronic HCV patients in whom different $\mathrm{HCV}$ genotypes are prevalent (Waked et al, 2020).

In contrast to the alleged effect of DAAs on increased HCC incidence rates, the results of this study came different. In this study, patients who got antiviral medication had a lower HCC incidence rate than those who did not. This study found a 5.5 percent incidence rate in patients who received antiviral therapy within 18 months of starting DAA therapy. During the same follow-up time, 11 percent of patients who did not get DAAs developed HCC. Interestingly, this occurred despite DAA receiving patients having a significantly higher degree of hepatic fibrosis and worse hepatic synthetic functions.

Comparing patients who received DAAs and controls regarding different clinical and laboratory variables before starting treatment showed significantly different values for main synthetic hepatic functions. DAA patients had lower values for serum albumin and higher values for mean INR and total bilirubin. The highest statistical significance was toward INR before treatment, which was higher in the DAA receiving group $(1.17 \pm 0.19)$ versus $(1.07 \pm 0.10)$ in controls with a highly significant $p$-value $<0.01$. This significant difference was in main synthetic hepatic functions could be a risk factor for developing HCC and would predict worse outcomes in DAA receiving patients (Conti et al, 2016). However, the DAA receiving group had a lower incidence of HCC compared to controls.

Comparing stages of hepatic fibrosis between both groups showed that the DAA receiving group had significantly more advanced hepatic fibrosis stages than the control group. $63 \%$ of DAA group patients had F4 stage, compared to $40.5 \%$ in controls. Also, $11.5 \%$ of the DAA group had F3 stage compared to only $6.5 \%$ in the control group. This discrepancy is another risk factor supposing the DAA received group to have an expectant higher $\mathrm{HCC}$ incidence than the control group (Singh et al, 2013). However, when compared to controls, the DAA group had a lower incidence of HCC. These findings support DAA's protective role in chronic HCV patients with advanced fibrosis.

The present results agreed with Calvaruso et al. (2018), reported that the HCC incidence decreased among HCV patients treated with DAA. The present results agreed with Kanwal et al. (2017) in USA who reported that among DAA patients treated, SVR was associated with a considerable reduction in the HCC risk, and that they did not find any evidence to suggest that DAAs promote HCC. But, in patients with SVR, the absolute risk of HCC remained high with established cirrhosis. Shiha et al. (2020) in Egypt determined the incidence of $\mathrm{HCC}$ in chronic hepatitis $\mathrm{C}$ patients genotype IV with liver cirrhosis and advanced liver fibrosis after achieving SVR following DAA treatment in a prospective large cohort of $\mathrm{HCV}$ patients with long follow-up. They concluded that the incidence of HCC was reduced in chronic hepatitis $C$ genotype 4 patients with liver cirrhosis (F4) and ad- 
vanced hepatic fibrosis (F3) who achieved SVR following DAA therapy.

The present results disagreed with Tayyab et al. (2020). They reported that HCV patients treated with a DAA based regimen were at a higher risk of incident HCC. However, with close observation, the higher risk was numerical and statistical significance was not achieved, and assumed increased risk was in HCV patients with genotype 3 only. Also, the present results disagreed with Kozbial et al, (2016), who reported an incidence of HCC in patients with cirrhosis shortly after the interferon free DAA regimen. In their observation, 16/198 patients who received DAA therapy developed HCC 48 weeks of follow up, with an incidence rate of $8.1 \%$. But, incidence rate did not express De novo HCC after DAA therapy.

Reig et al. (2016) in Spain reported an unexpected high rate and pattern of tumor recurrence coinciding with $\mathrm{HCV}$ clearance and, although based in a very small cohort of patients, should be taken as a note of caution and prime a large scale assessment that exceeds the individual investigators capacity. Donato et al. (2016) in Italy reported that there was no control arm to compare the $\mathrm{HCC}$

incidence with other HCV patients who did not receive DAAs. El Kassas et al. (2018) in Egypt reported that Liver transplantation is considered the ultimate solution for patients with end-stage chronic liver disease or acute liver failure. They added that patients with liver transplant need special care starting from preoperative preparation, surgical intervention ending with postoperative care. Transplanted patients have to receive immunosuppressive therapy to prevent rejection. Liu et al. (2020) in Taiwan reported that HCC recurrence rates and patterns after initiation of antiviral therapy did not differ between patients who received IFN-based therapy and DAA therapy.

\section{Conclusion}

Clearance of HCV infection using direct acting antiviral therapy decreases risk of HCC occurrence, but it didn't abolish it. Interestingly, decreased incidence occurred despite DAAs receiving patients having a significantly higher degree of hepatic fibrosis. We recommend future studies with a larger number of patients and a longer duration of follow up to determine more precisely the long-term risk of HCC incidence and the risk factors affecting it.

Authors' contributions: All authors equally contributed in the study.

\section{References}

Calvaruso, V, Cabibbo G, Cacciola I, Petta S, Madonia S, et al, 2018: Incidence of hepatocellular carcinoma in patients with $\mathrm{HCV}$-associated ci-rrhosis treated with direct-acting antiviral agents. Gastroenterology 155, 2:411-21.

Chevaliez, S, Feld, J, Cheng, K, Wedemeyer, H, Sarrazin, C, et al, 2018: Clinical utility of $\mathrm{HCV}$ core antigen detection and quantification in diagnosis and management of patients with chronic hepatitis $\mathrm{C}$ receiving an all-oral, interferon-free regimen. Antivir. Ther. 23, 3:211-7

Di Bisceglie, AM, Stoddard, AM, Dienstag, J L, Shiffman, ML, Seeff, LB, et al, 2011: Excess mortality in patients with advanced chronic hepatitis $\mathrm{C}$ treated with long-term peg-interferon. Hepatology 53, 4:1100-8.

Donato, MF, Invernizzi, F, Rossi, G, Iavarone, M, 2017: Interferon-free therapy of hepatitis $\mathrm{C}$ during wait list and post-transplant risk of hepatocellular carcinoma recurrence. J. Hepatol. 67, 6:1355-6

El Kassas, M, Alboraie, M, Al Balakosy, A, Abdeen, N, Afify, S, et al, 2018: Increased recurrence rates of hepatocellular carcinoma after DAA therapy in a hepatitis C-infected Egyptian cohort: A comparative analysis. J. Viral Hepat. 25:623-30

Hézode C, Asselah T, Reddy KR, Hassanein T, Berenguer $\mathrm{M}$, et al, 2015: Ombitasvir plus paritaprevir plus ritonavir with or without ribavirin in treatment-naive and treatment-experienced patients with genotype 4 chronic hepatitis $C$ virus infection (PEARL-I): A randomized, open-label trial. Lancet 385:2502-9.

Kanwal F, Kramer, J, Asch, SM, Chayanupatkul, M, Cao, Y, et al, 2017: Risk of hepatocellular cancer in HCV patients treated with direct-acting antiviral agents. Gastroenterology 153, 4:996-1005.

Kim, KH, Jang, BK, Chung, WJ, Hwang, JS, 
Kweon, YO, et al, 2011: Peg-interferon alpha and ribavirin combination therapy in patients with hepatitis $\mathrm{C}$ virus-related liver cirrhosis. Korean J. Hepatol.17, 3:220-2.

Kozbial, K, Moser, S, Schwarzer, R, Laferl, H, Al-Zoairy, R, et al, 2016: Unexpected high incid-ence of hepatocellular carcinoma in cirrhotic patients with sustained virologic response following interferon-free direct-acting antiviral treatment. J. Hepatol 65, 4:856-8.

Kwo, PY, Cohen, SM, Lim, JK, 2017: ACG clinical guideline: Evaluation of abnormal liver chemistries. Am. J. Gastroenterol. 112, 1:1835-8 Liu, YC, Yeh, CT, Lin, KH, 2020: Cancer stem cell functions in hepatocellular carcinoma and co-mprehensive therapeutic strategies. Cells 26, 9 (6)1331 doi:10.3390/

Majumdar, A, Kitson, MT, Roberts, SK, 2016: Systematic review: Current concepts and challe-nges for the direct-acting antiviral era in hepatitis $\mathrm{C}$ cirrhosis. Alimentary pharmacology \& therape-utics 43, 12:1276-92.

Omran, D, Alboraie, M, Zayed, RA, Wifi, MN, Naguib, M, et al, 2018: Towards hepatitis $\mathrm{C}$ virus elimination: Egyptian experience, achievements and limitations. Wld. J. Gastroenterol. 24, 38: 4330-40.

Page, K, Melia, MT, Veenhuis, RT, Winter, M, Rousseau, KE, et al, 2021: Randomized trial of a vaccine regimen to prevent chronic HCV infection. N. Engl. J. Med. 384, 6:541-9

Raad, II, Chaftari, AM, Torres, HA, Ayoub, E M, Narouz, LI, et al, 2018: Challenge of hepatitis C in Egypt and hepatitis B in Maurita nia. World J. Hepatol. 10, 9:549-57.

Reig, M, Marino, Z, Perello, C, et al, 2016: Unexpected early tumor recurrence in patients with hepatitis $\mathrm{C}$ virus-related hepatocellular carcinoma undergoing interferon-free therapy: a note of caution. J. Hepatol. 65:719-26

Sagnelli, E, Macera, M, Russo, A, Coppola, N, Sagnelli, C, 2020: Epidemiological and etiologic-al variations in hepatocellular carcinoma. Infecti-on 48, 1:7-17

Shiha, G, Mousa, N, Soliman, R, Nnh Mikhail, N, Adel Elbasiony, M, et al, 2020: Incidence of HCC in chronic hepatitis $\mathrm{C}$ patients with advanced hepatic fibrosis who achieved SVR following DAAs: A prospective study. J. Viral Hepatitis 27, 7:671-9.

Singh, S, Fujii, LL, Murad, MH, Wang, Z, Asrani SK, et al, 2013: Liver stiffness is associated with risk of decompensation, liver cancer, and death in patients with chronic liver diseases: a systematic review and meta-analysis. Clin.. Gastroenterol. Hepatol.11, 12:1573-84.

Tayyab, GUN, Rasool. S, Nasir, B, Rubi, G, Abou-Samra, AB, et al, 2020: Hepatocellular carcinoma occurs frequently and early after treatment in HCV genotype 3 infected persons treated with DAA regim-ens. BMC Gastroenterol.Apr 6; 20(1):93. doi: 10.1186/

Waked, I, Esmat, G, Elsharkawy, A, El-Serafy, M, Abdel-Razek, W, et al, 2020: Screening and treatment program to eliminate hepatitis $\mathrm{C}$ in Egypt. N. Engl. J. Med. 382.12:1166-74.

Westbrook, RH, Dusheiko, G, 2014: Natural history of hepatitis C. J. Hepatol. 61.1:S58-68.

\section{Explanation of figure}

Fig. 1: Comparison between patients who received DAA and not receiving group as regards HCC incidence.

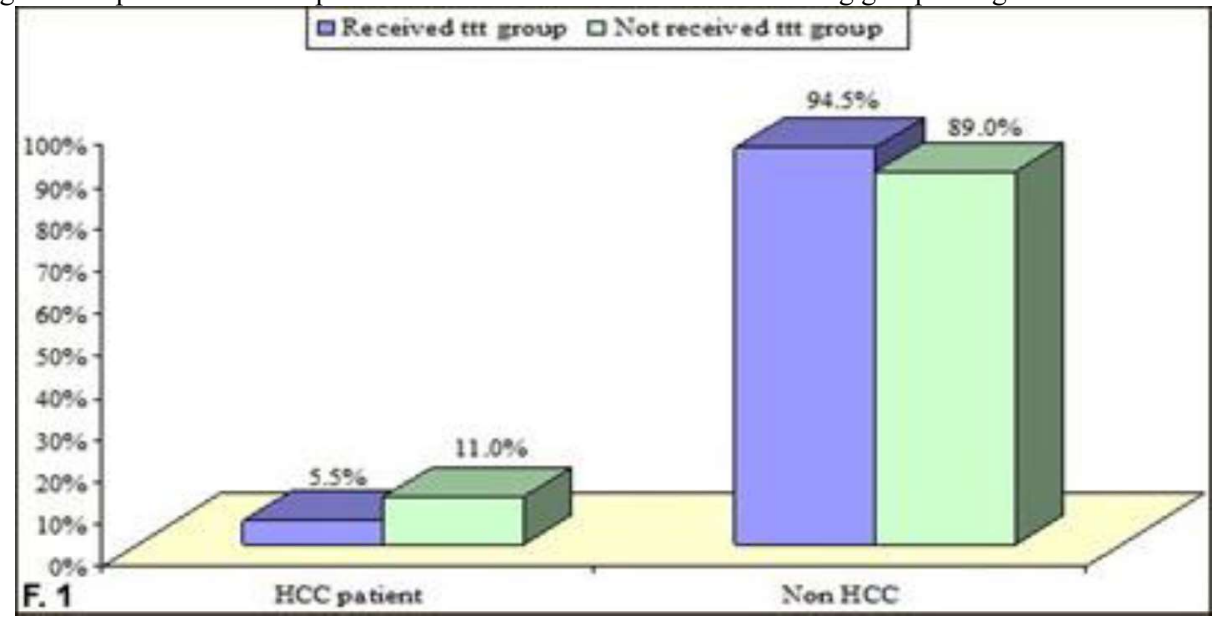

